\title{
Penerapan Model Pembelajaran Kooperatif Metode Jigsaw Learning Untuk Meningkatkan Hasil Belajar IPA Siswa Materi Induksi Elektromagnetik Kelas IX Di SMP Budhi Luhur Pekanbaru
}

\author{
DARMAWENY \\ Dinas Pendidikan Kota Pekanbaru \\ SMP Budhi Luhur Pekanbaru \\ J1. Paus Ujung, Limbungan Baru, Kec. Rumbai Pesisir, Pekanbaru Telp. (0761) 51095 \\ E-mail : darmaweny_2015@yahoo.co.id
}

\begin{abstract}
This study aims to determine the improvement of students' learning outcomes in the subjects of Science on Electromagnetic Induction materials with the application of cooperative learning method Jigsaw Learning in class IX in SMP Budhi Luhur Pekanbaru. This form of research is a classroom action research with as many as two rounds (Cycle). Each round is done with four stages of planning, implementation, observation and reflection. The subjects of this study are the students of class IX in SMP Budhi Luhur Pekanbaru with a total of 26 students consisting of 13 male students and 13 female students. The data obtained in the form of science learning outcomes obtained from the test and observation sheet of teaching and learning activities. Data collection methods used include test, observation and documentation. From the results in the first cycle of student learning outcomes to $40 \%$ with inactive classification. While in the second cycle of students in learning results increased to $60 \%$ with a very active classification. This situation indicates that the improvement in the learning process of Science with the application of cooperative learning metdod Jigsaw Learning in science subjects in class IX students at SMP Budhi Luhur Pekanbaru can be said fully successful.
\end{abstract}

Keywords: Science, Electromagnetic Induction, Jigsaw Learning

Pengembangan Kurikulum Tingkat Satuan Pendidikan (KTSP), perlu memperhatikan kepentingan dan kekhasan daerah, sekolah dan peserta didik. Model pembelajaran dengan kurikulum yang disebutkan di atas adalah mengacu pada pembelajaran kreatif, siswa lebih aktif dalam pembelajaran sedangkan guru bertindak sebagai motivator dan fasilitator. Artinya dalam pembelajaran guru mendorong siswa untuk berkreatif dalam pembelajaran dan guru mengimformasikan materi pembelajaran, siswa diberi kesempatan untuk mengeksploitasikan (menggali) materi yang dipelajari. Dengan demikian model pembelajaran konvensional, dimana guru mendominasi dalam pembelajaran harus sudah ditinggalkan. Oleh sebab itu guru harus dapat menciptakan suasana belajar yang menyenangkan sehingga dapat menjadikan proses pembelajaran lebih efektif, dan dapat mencapai hasil belajar yang memuaskan. Dengan Model
Pembelajaran Koorperatif (Coorperative Learnig) Metode Jigsaw Learning, menunjukkan salah satu Model Pembelajaran yang dapat menciptakan suasana pembelajaran tersebut.

Proses pembelajaran IPA hasil belajar siswa umumnya dibawah KKM, motivasi belajar siswa pun rendah, sebagian siswa tidak menjawab pertanyaan guru ketika ditanya, jarang ada siswa yang bertanya kepada guru mengenai penjelasan materi yang diajarkan, ketika guru memberikan ulangan individu masih banyak siswa yang menyontek. Selain permasalahan di atas masih cenderung persial artinya ada pengelompokkan siswa yang pandai dengan siswa yang kurang pandai.

Berdasarkan uraian diatas terungkap bahwa Pembelajaran IPA di kelas IX masih kurang berhasil, minat belajar IPA kurang dan hasil belajar siswa belum sesuai standar yang telah di 
122 Penerapan Model Pembelajaran Kooperatif Metode Jigsaw Learning Untuk Meningkatkan Hasil Belajar IPA Siswa Materi Induksi Elektromagnetik Kelas IX Di SMP Budhi Luhur Pekanbaru (Darmaweny)

tetapkan. Oleh karena itu perlu ada tindakan untuk mengatasi permasalahan pembelajaran IPA di kelas tersebut, yaitu dengan tetap menerapkan metode diskusi namun pelaksanaannya menggunakan model Pembelajaran Kooperatif Jigsaw Learning.

Jigsaw Learning adalah belajar melalui tukar delegasi antar kelompok (Rusman, 2012: 220). Model Jigsaw Learning adalah suatu model pembelajaran kooperatif yang terdiri dari beberapa anggota dalam satu kelompok yang bertanggung jawab atas penguasaan bagian materi belajar dan mampu mengajarkan bagian tersebut kepada anggota lain dalam kelompoknya.

Belajar merupakan kebutuhan yang harus dipenuhi oleh setiap manusia. Belajar adalah kegiatan berproses dan merupakan unsur yang penting dalam penyelenggaraan pendidikan. Sedangkan keberhasilan pencapaian tujuan pendidikan sangat tergantung pada keberhasilan proses belajar siswa di sekolah dan dilingkungan sekitarnya.

Belajar memiliki beberapa defenisi dan teori yang dikemukakan oleh beberapa ahli pendidikan. Menurut Syah yang dikutif oleh Jihad mengatakan bahwa belajar merupakan tahapan perubahan perilaku siswa yang relative positif dan mantap sebagai hasil interaksi dengan lingkungan yang melibatkan proses kognitif. Tahapan dalam belajar tergantung pada fase-fase belajar. Menurut Witting ada tiga tahapan dalam belajar, antara lain :

1. Tahapan Acquisition, yaitu tahapan perolehan informasi

2. Tahapan, Storage, yaitu tahapan menyimpan informasi; dan

3. Tahapan Retrieval, yaitu tahapan pendekatan kembali informasi.

Pembalajaran adalah suatu yang dilakukan oleh siswa, bukan dibuat untuk siswa. Pembeljaran pada dasarnya merupakan upaya pendidik untuk membantu peserta didik melakukan kegiatan belajar.

Diklat Review: Jurnal Manajemen Pendidikan dan Pelatihan
Menurut Slavin yang dikutif oleh Isjoni, Coorverative Learning adalah suatu model pembelajaran dimana siswa belajar dan bekerja dalam kelompokkelompok kecil secara kolaboratif yang anggotanya 4-6 orang dengan struktur heterogen. Menurut Hadiyati, H., \& Fatkhurahman, F. (2017) pentingnya penerapan metode pembelajaran yang tepat dalam menghasilkan capaian pembelajaran yang optimal.

Jigsaw Learning adalah belajar melalui tukar delegasi antar kelompok (Rusman, 2012: 220). Model Jigsaw Learning adalah suatu model pembelajaran kooperatif yang terdiri dari beberapa anggota dalam satu kelompok yang bertanggung jawab atas penguasaan bagian materi belajar dan mampu mengajarkan bagian tersebut kepada anggota lain dalam kelompoknya. Model Jigsaw Learning merupakan salah satu model yang dapat dipakai dalam pembelajaran, termasuk dalam pelajaran IPA.

Secara garis besar langkahlangkahnya adalah sebagai berikut:

a. Pilihlah materi pelajaran yang dapat dibagi menjadi beberapa segmen (bagian).

b. Bagilah siswa menjadi beberapa kelompok sesuai dengan jumlah segmen yang ada. Jika jumlah siswa ada 25 sementara jumlah segmen yang ada adalah 5, maka masing-masing kelopmok terdiri dari 5 orang.

c. Setiap kelompok mendapat tugas membaca, memahami dan mendiskusikan serta membuat ringksan materi pelajaran yang berbeda-beda.

d. Setiap kelompok mengirimkan anggotanya ke kelompok lain untuk menyampaikan apa yang telah mereka pelajari di kelompoknya.

e. Kembalikan suasana kelas seperti semula kemudian tanyakan sekiranya ada persoalan-persoalan

E-ISSN:2598-6449 P-ISSN: 2580-4111 Vol. 2, No. 2, Agustus 2018 
yang tidak terpecahkan dalam kelompok.

f. Sampaikan beberapa pertanyaan kepada siswa untuk mengecek pemahaman mereka terhadap materi.

g. Guru melakukan kesimpulan dan tindak lanjut. Tujuan penerapan strategi ini adalah untuk melatih peserta didik agar terbiasa berdiskusi dan bertanggung jawab secara individu untuk membantu memahamkan tentang suatu materi pokok kepada teman sekelasnya.

\section{METODE}

Penelitian ini bertujuan meningkatkan hasil belajar IPA khususnya dalam Kompetensi Dasar 4.3 Menerapkan konsep induksi eloktromagnetik untuk menjelaskan prinsip kerja beberapa alat yang memanfaatkan prinsip induksi elektromagnetik di Kelas IX di SMP Budhi Luhur Pekanbaru, melalui model pembelajaran kooperatif dengan Jigsaw Learning.

Penelitian ini dilakukan di kelas IX pada SMP Budhi Luhur Pekanbaru beralamat di Jalan Paus Ujung, Limbungan Baru, Kec. Rumbai Pesisir, Kota Pekanbaru. Sedangkan waktu penelitian dilaksanakan pada bulan Januari sampai dengan bulan Maret 2018. Subyek penelitian ini adalah siswa kelas IX pada SMP Budhi Luhur Pekanbaru Semester Genap tahun 2018 yang berjumlah sebanyak 26 siswa, yang terdiri dari 13 siswa laki-laki dan 13 siswa perempuan.

Penelitian ini dilakukan bersamasama antara peneliti dan kolaborator yaitu guru Bahasa Inggris. Dalam penelitian tindakan peneliti menggunakan Desain Model Kurt Levi, dimana konsep pokok dari penelitian terdiri dari empat siklus yaitu :

1. Perencanaan (Plan)

2. Tindakan (Action)

3. Pengamatan (Obesevation)

4. Refleksi (Reflection)
Tindakan yang dilaksanakan dalam penelitian ini adalah Penerapan Model Pembelajaran Kooperatif metode Jigsaw Learning yang disajikan sebanyak empat kali pertemuan dalam dua siklus. Adapun uraian tentang penyajian kelas yang dilaksanakan dari setiap siklus adalah sebagai berikut:

\section{Siklus I (Pertama).}

Pada tahap ini peneliti telah mempersiapkan instrumen penelitian yang terdiri dari perangkat pembelajaran dan instrumen pengumpulan data. Perangkat pembelajaran terdiri dari silabus, rencana pelaksanaan pembelajaran yang disusun untuk empat kali pertemuan, lembar kerja siswa. Instrumen pengumpulan data yang digunakan adalah lembar pengamatan untuk setiap kali pertemuan ,lembar pengamatan aktivitas guru, lembar pengamatan aktivitas siswa dan perangkat tes hasil belajar pendidikan kewarganegaraan untuk ulangan harian I dan ulangan harian II. Perangkat tes hasil belajar terdiri dari kisi-kisi penulisan soal ,naskah soal dan alternatif jawaban

\section{Siklus II (Kedua)}

Pada tahap ini, agar siklus kedua terlaksana lebih baik, peneliti berdiskusi dengan guru bidang studi Ilmu Pengetahuan Alam (IPA) SMP Budhi Luhur Pekanbaru untuk membahas hal-hal yang harus dilakukan dalam meningkatkan hasil belajar siswa pada pertemuan dan materi berikutnya sebagaimana yang terdapat pada refleksi siklus I. Peneliti juga mempersiapkan perangkat pembelajaran berupa RPP, LKS, soal ulangan harian II, jawaban soal ulangan harian II, dan lembar aktivitas guru dan aktivitas siswa selama pembelajaran berlangsung. Pembelajaran pada siklus II ini dilakukan dua kali pertemuan dan satu kali ulangan harian.

Setelah itu, guru menjelaskan materi tentang kelangsungan hidup sesuai dengan model pembelajaran yang ditetapkan yaitu model pembelajaran langsung. Guru menjelaskan materi secara bertahap dengan disertai contoh soal dan bersama-sama

\section{HASIL}


124 Penerapan Model Pembelajaran Kooperatif Metode Jigsaw Learning Untuk Meningkatkan Hasil Belajar IPA Siswa Materi Induksi Elektromagnetik Kelas IX Di SMP Budhi Luhur Pekanbaru (Darmaweny)

siswa menjawab contoh soal tersebut. Guru berusaha membuat siswa lebih aktif dalam menjawab contoh soal tersebut. Guru menjanjikan akan memberikan nilai tambahan kepada siswa yang aktif, yang bisa menjawab pertanyaan-pertanyaan untuk LKS berikutnya. Siswa menjadi lebih antusias untuk bisa menjawab pertanyaan pada LKS berikutnya.

Setelah pertanyaan selesai dijawab, guru memberikan latihan lanjutan kepada siswa untuk dikerjakan secara individu. Siswa langsung mengerjakan latihan lanjutan tersebut, tetapi masih ada siswa yang bekerjasama dengan teman di sampingnya. Guru mengingatkan kembali kepada siswa untuk mengerjakannya secara individu. Setelah waktu yang diberikan berakhir, guru meminta siswa untuk mengumpulkan lembar jawaban.

Setelah siswa mengumpulkan lembar jawaban, guru mengarahkan siswa untuk menyimpulkan materi pelajaran dengan melakukan tanya jawab secara klasikal. Diakhir pembelajaran guru memberikan tindak lanjut berupa nasehat untuk belajar di rumah tentang materi yang telah dipelajari dari pertemuan ke tiga dan keempat, karena pertemuan selanjutnya diadakan ulangan harian II (dua). Jadi, siswa harus giat belajar.

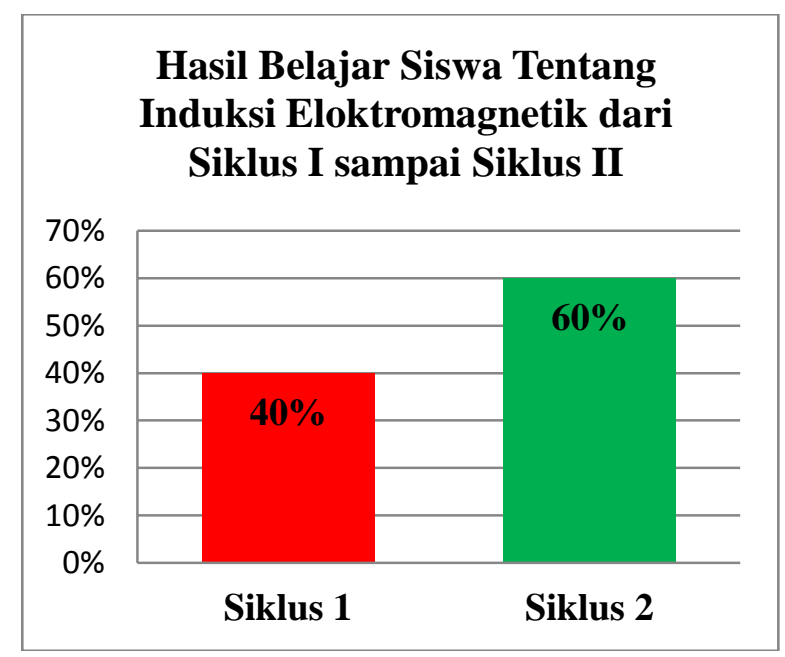

Data yang dianalisa dalam penelitian ini adalah data tentang aktivitas siswa dan guru selama proses pembelajaran berlangsung serta analisis keberhasilan tindakan dalam dua siklus selama penerapan model pembelajaran kooperatif metode Jigsaw Learning.

\section{PEMBAHASAN}

Penerapan model pembelajaran kooperatif metode Jigsaw Learning dalam pembelajaran langsung telah berjalan sesuai dengan rencana dan dapat meningkatkan hasil belajar IPA siswa. Dari keseluruhan pertemuan aktivitas guru dan siswa selama proses pembelajaran telah mengalami peningkatan pemahaman siswa terhadap langkah-langkah penerapan pembelajaran kooperatif metode Jigsaw Learning .

Siklus kedua sudah berjalan lebih baik dari siklus pertama. Siswa sudah terbiasa dan mengerti dengan langkahlangkah pembelajaran, sehingga tidak terlalu banyak melakukan kesalahan. Sudah mulai banyak siswa yang aktif dibandingkan siklus I walaupun guru harus selalu memberikan motivasi agar siswa aktif dalam proses pembelajaran. Pada siklus kedua ini peneliti tidak melakukan perencanaan untuk siklus berikutnya, hasil refleksi siklus kedua ini peneliti serahkan kepada guru sebagai bahan masukan untuk perbaikan ke depan.

Berdasarkan hasil analisis data penelitian yang telah dikemukakan, dapat diambil beberapa kesimpulan sebagai berikut: Peningkatan kemampuan hasil belajar Ilmu Pengetahuan Alam (IPA) pada siswa yang memperoleh model pembelajaran melalui penerapan metode Jigsaw Learning dalam pembelajaran langsung dibandingkan dengan siswa yang memperoleh pembelajaran biasa berbeda signifikan, dengan hasil yang relatif lebih baik. Hal ini sejalan dengan apa yang dikatakan Hadiyati, H., Fatkhurahman, F., \& Suroto, B. (2017) bahwa melalui penelitian tindakan kelas, maka berbagai persoalan di kelas dapat dicarikan solusi dan berdampak terhadap hasil belajar siswa.

\section{SIMPULAN}

Peningkatan kemampuan hasil belajar Ilmu Pengetahuan Alam (IPA) pada siswa yang memperoleh model 
pembelajaran melalui penerapan Jigsaw Learning dalam pembelajaran langsung dibandingkan dengan siswa yang memperoleh pembelajaran biasa berbeda signifikan, dengan hasil yang relatif lebih baik. Melalui pembelajaran Jigsaw Learning, guru dapat dengan mudah merespon potensi atau modalitas siswa dalam setiap kelompok belajar, apakah tergolong kepada kelompok Visual, atau kelompok Auditorial atau kelompok Kinestetik. Dengan demikian seorang guru yang profesional dapat lebih efektif melakukan kegiatan proses belajar mengajar, serta dengan mudah dapat merespon perbedaan - perbedaan potensi yang dimiliki peserta didiknya.

\section{DAFTAR RUJUKAN}

Asep Jihad, 2008, Evaluasi Pembelajaran, Yogyakarta : Multi Pressindo.

Hadiyati, H., Fatkhurahman, F., \& Suroto, B. (2017). Pelatihan Manajemen Penulisan Karya Tulis Ilmiah Bagi Tenaga Pendidik Di Smp N 3 Kampar Kiri Tengah. Dinamisia: Jurnal Pengabdian Kepada Masyarakat, 1(1, Des), 122-128.

Hadiyati, H., \& Fatkhurahman, F. (2017). Pelatihan Penulisan Jurnal Ilmiah Bagi Tenaga Pendidik (Guru SD) Di Kecamatan Siak Hulu Kabupaten Kampar. Jurnal Diklat Review, 1(1), 18-24.

Isjoni, 2007, Cooperative Learning, Bandung : alfabeta.

Nana, Sujana, 2004, Dasar-dasar Proses Belajar Mengajar, Bandung : Sinar Baru Algesindo

Ngalim Purwanto, 1988, Psikologi Pendidikan, Bandung : Remaja Karya.
Ngalim Purwanto, 2001, Prinsip-prinsip dan Teknik Evaluasi Pengajaran, Bandung : Remaja Rosda Karya.

Nurdin Ibrahim, 2000, Hubungan Tempat Tutorial Tatap Muka dengan Hasil Belajar Siswa SLTP Terbuka, Jurnal Teknodik, Oktober.

Nurmawati. 2012. Penggunaan Model Pembelajaran Kooperatif Tipe STAD Untuk Meningkatkan Hasil Belajar IPA Siswa Kelas IV SDS Bahreisy Surabaya. Surabaya: PGSD FIP Universitas Negeri Surabaya.

Peraturan Pemerintah, Nomor 19 Tahun 2005 tentang Standar Nasional Pendidikan, Jakarta : Departemen Pendidikan Nasional RI.

R E Slavin, 1994, A Practical Gaide To Cooperative Learning, USA : A Division Of Paramount Publishing.

Sukardi, 2004, Metodologi Peneltian Pendidikan Kompetensi dan Prakteknya, Jakarta : Bumi Aksara.

Undang-undang Republik Indonesia, Nomor 20 Tahun 2003 tentang Sistem Pendidikan Nasional, Jakarta : Depertemen Pendidikan Nasional RI.

Wina, Sanjaya, 2006, Strategi Pembelajaran, Jakarta : Prenada Media. 